\title{
Application of Artificial Neural Network in seismic reservoir characterization: a case study from Offshore Nile Delta
}

\author{
Adel Othman ${ }^{1} \cdot$ Mohamed Fathy $^{1} \cdot$ Islam A. Mohamed ${ }^{2}$ \\ Received: 26 October 2020 / Revised: 10 December 2020 / Accepted: 4 January 2021 / Published online: 19 January 2021 \\ (C) The Author(s) 2021
}

\begin{abstract}
The Prediction of the reservoir characteristics from seismic amplitude data is a main challenge. Especially in the Nile Delta Basin, where the subsurface geology is complex and the reservoirs are highly heterogeneous. Modern seismic reservoir characterization methodologies are spanning around attributes analysis, deterministic and stochastic inversion methods, Amplitude Variation with Offset (AVO) interpretations, and stack rotations. These methodologies proved good outcomes in detecting the gas sand reservoirs and quantifying the reservoir properties. However, when the pre-stack seismic data is not available, most of the AVO-related inversion methods cannot be implemented. Moreover, there is no direct link between the seismic amplitude data and most of the reservoir properties, such as hydrocarbon saturation, many assumptions are imbedded and the results are questionable. Application of Artificial Neural Network (ANN) algorithms to predict the reservoir characteristics is a new emerging trend. The main advantage of the ANN algorithm over the other seismic reservoir characterization methodologies is the ability to build nonlinear relationships between the petrophysical logs and seismic data. Hence, it can be used to predict various reservoir properties in a 3D space with a reasonable amount of accuracy. We implemented the ANN method on the Sequoia gas field, Offshore Nile Delta, to predict the reservoir petrophysical properties from the seismic amplitude data. The chosen algorithm was the Probabilistic Neural Network (PNN). One well was kept apart from the analysis and used later as blind quality control to test the results.
\end{abstract}

Keywords Reservoir characterization $\cdot$ Neural Network $\cdot$ Seismic inversion $\cdot$ Nile Delta $\cdot$ Sequoia

\section{Introduction}

The Sequoia field, the case study, is one of the major gas fields in both WDDM and Rosetta concessions (Fig. 1) Samuel et al. (2003). The field is located on the north-western margin of the outer slope of the Nile Delta, approximately $50 \mathrm{~km}$ from the nearest shoreline Mohamed et al. (2017).

Different inversion methodologies have been proposed for reservoir properties characterization to predict rock/fluid properties from seismic amplitude data. Generally, rock properties (porosity for example) are better-resolved than pressures and

Communicated by: H. Babaie

Mohamed Fathy

m.fathi@azhar.edu.eg

Al-Azhar University, Nasr City, Cairo, Egypt

2 Rashid Petroleum Company (Rashpetco), New Maadi, Cairo, Egypt saturations. Russell (2014) presented a comprehensive review of the modern AVO and inversion techniques. Each of these methods has its advantages and disadvantages. However, one of the common challenges is the prediction of the petrophysical properties, especially the saturation, considering their no direct relationships with seismic elastic attributes.

To overcome this challenge, we implemented one of the Artificial Intelligence (AI) algorithms for seismic reservoir characterization. AI is a modern branch of computer sciences. It has a wide range of applications that cover almost every aspect of our modern lifestyle. Many algorithms were proposed to solve geophysical problems. Artificial Neural Network (ANN) is one of the most promising algorithms. Neural networks were first inspired by the architecture of neurons in the human brain. ANN inversion gained popularity over the last decades because of its ability to establish nonlinear relationships between the input and the target property. At well locations, it "learns" the relationships that link the target $\log$ and the seismic attributes. Then, it applies that to 


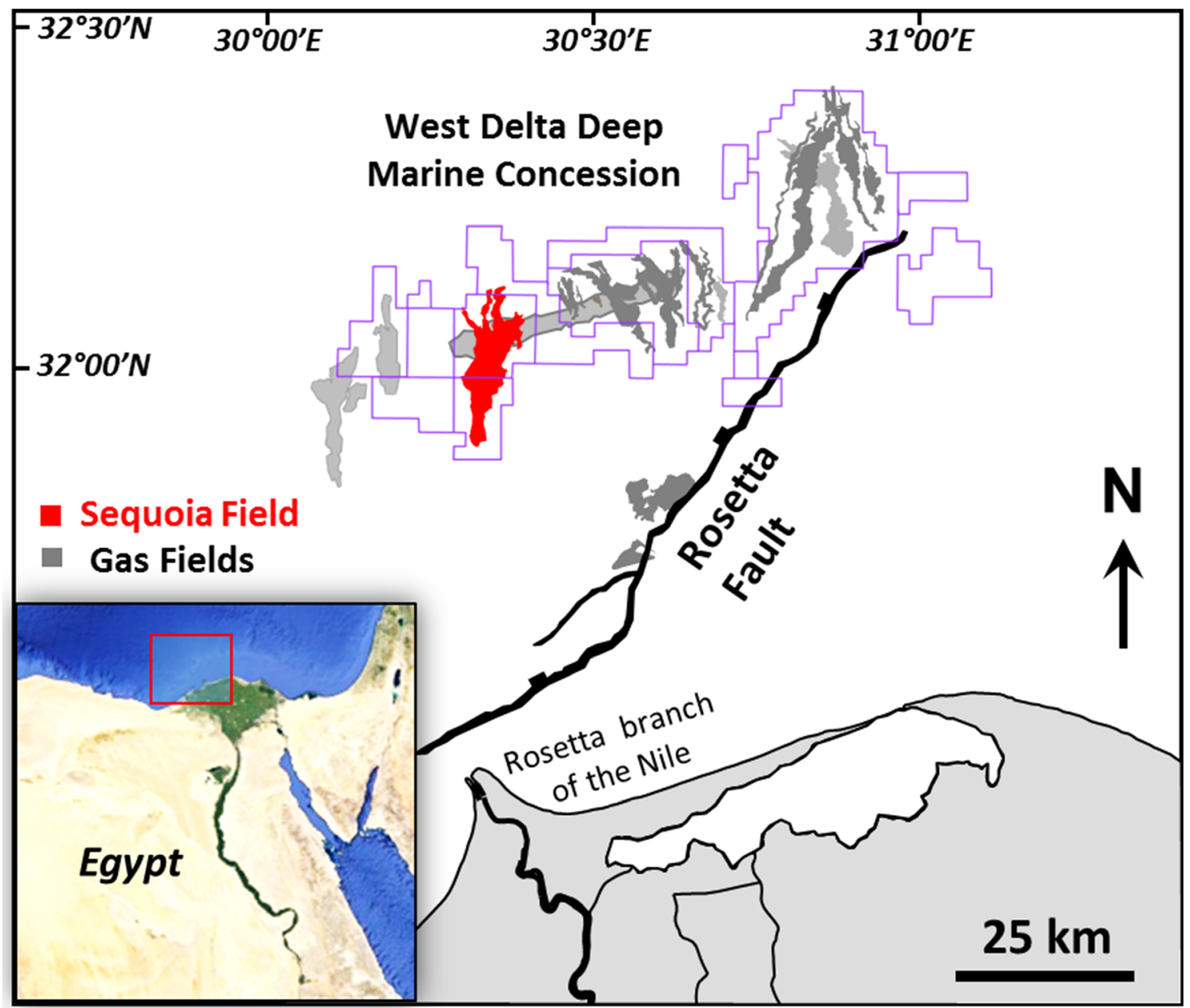

Fig. 1 An index map shows the offshore Nile Delta basin. The study area is defined by the red box. Sequoia field is colored in red while the other Pliocene gas fields are colored in grey. Modified from Samuel et al. (2003)

predict the target property in a 3D domain. Theoretically, the ANN can predict any reservoir property.

In this study, we have implemented an integrated approach that combines the Hampson et al. (2001)proposal for the ANN training and validation, and Mohamed et al. (2014) proposal for the data conditioning. The output of the study was 3D volumes of and Shale Volume $\left(V_{s h}\right)$, Effective Porosity $(\Phi)$, and Water Saturation $\left(S_{w}\right)$. Blind-well tests were performed to the resulted volumes for quality control (QC) and assessment purposes.

\section{Geologic setting}

Nile Delta basin is one of the emerging gas provinces worldwide. Numerous gas discoveries of multi-trillion cubic feet (TCF) during the last decades proves its remaining reserves. The estimation of the Nile Delta basin oil and gas reserves, in 2010, was reported Kirschbaum et al. (2010) as follows: the estimated mean value for the recoverable oil is 1.8 billion barrels, the estimated mean value for the recoverable gas is $223 \mathrm{TCF}$, and finally, the natural gas liquids are about 6 billion barrels. Five years later, the giant "Zohr" discovery proved the high hydrocarbon-potentiality of this basin. The first well found a $654 \mathrm{~m}$ of biogenic gas. The calculated volume reaches 30 TCF Cozzi et al. (2018).

The first phase of exploration across the Nile Delta Basin targeted the onshore Messinian incised valleys Adel et al. (2017a, b). The subsequent exploration phases targeted the offshore extension of this play and other Pliocene submarine slope reservoirs Tharwat et al. (2014). Many discoveries were made and currently producing gas such as the gas fields of Rosetta concession and West Delta Deep Marine (WDDM) concession (Fig.2) Rio et al. (1991).

The Sequoia field was discovered by an exploration well, in 2000, and subsequently appraised by three wells (2000-2002). All wells were drilled based on seismic direct hydrocarbon indicators (i.e. bright and flat 


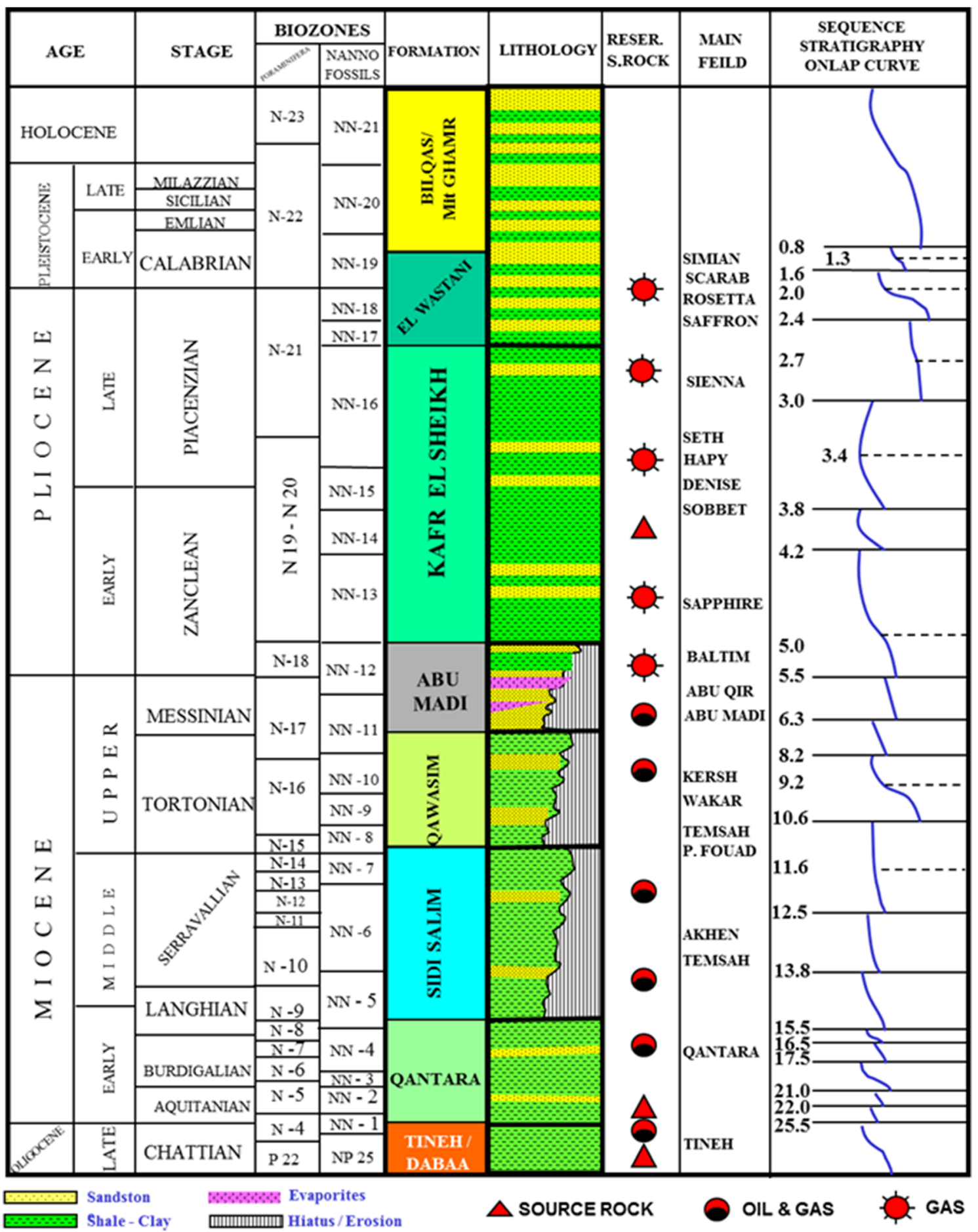

Fig. 2 Nile Delta stratigraphic column and hydrocarbon system. Modified from Rio et al. (1991)

spots) and found gas sand reservoirs. Later in 2008, the field was developed with six wells. In 2009, the production had started, and the cumulative production reached approximately 665 billion cubic feet.

The Sequoia field is a Pliocene (El-Wastani formation) submarine slope canyon system. This canyon is filled with many turbiditic channelized reservoirs Cross et al. (2009). The southern part of Sequoia is confined to a relatively narrow and well-defined valley incision (approximately $5 \mathrm{~km}$ wide). In contrast, the northern part of the field occupies a much wider incised valley which, in addition to the main central channel, contains many branches (more than $20 \mathrm{~km}$ wide). 


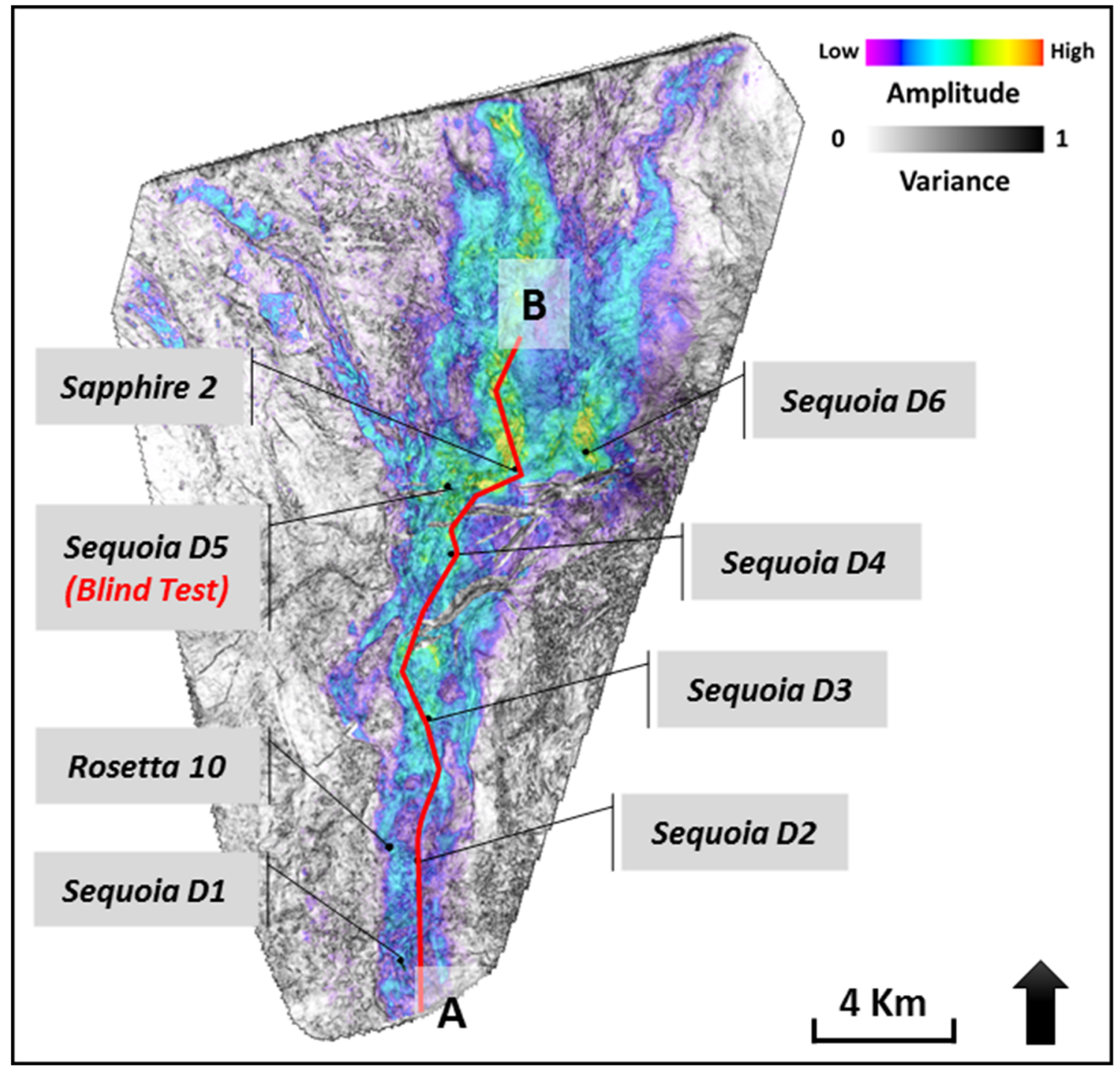

Fig. 3 Root-mean-square amplitude map for the Sequoia channel overlaying the base of the channel's variance slice. Locations of the study wells and the blind well are shown. Modified from Mohamed et al. (2017)

The total length of the field exceeds $30 \mathrm{~km}$ (Fig.3). The wells penetrate areas with different gas-water contacts (GWC), indicating compartmentalization and complexity within the channel complex. GWCs get progressively deeper to the north. This is most likely due to aquifer perching as a result of fault compartmentalization (Fig. 3).

The Sequoia reservoir, generally, is a thick succession (up to $200 \mathrm{~m}$ ) that is fining upward of sandstones and mudstones. The reservoir's base is defined by a major incision that represents the base of the canyon (Fig. 4). As presented by Mohamed et al. (2017), the canyon is filled by many smaller channels that are stacked together to form the final shape of the reservoir (Fig.3). The pay gas sand is approximately $77 \mathrm{~m}$. The average water saturation for the reservoir is $34 \%$ while the average effective porosity is $24 \%$.

\section{Methodology}

The input data for this study include; seismic amplitude, seismic inversion, and well-log data sets. The seismic amplitude data is represented by a reprocessed 3D full-stack seismic volume that covers the area of interest. The acquisition of this survey was in 2006 while the reprocessing was in 2014. The total record duration is $6 \mathrm{~s}$ and the sample rate is $4 \mathrm{~ms}$. The seismic prestack inversion volumes include the fundamental elastic volumes; P-Impedance $\left(\mathrm{I}_{\mathrm{P}}\right)$, S-Impedance $\left(\mathrm{I}_{\mathrm{S}}\right)$, and Density $\left(D_{n}\right)$. In addition, other derived volumes include; Pwave velocity $\left(V_{P}\right)$, S-wave velocity $\left(V_{S}\right), V_{P} V_{S}$ ratio, Lambda-Rho $(\lambda \rho)$, and Mu-Rho $(\mu \rho)$ volumes. The wells used in the study are sorted into two exploration 


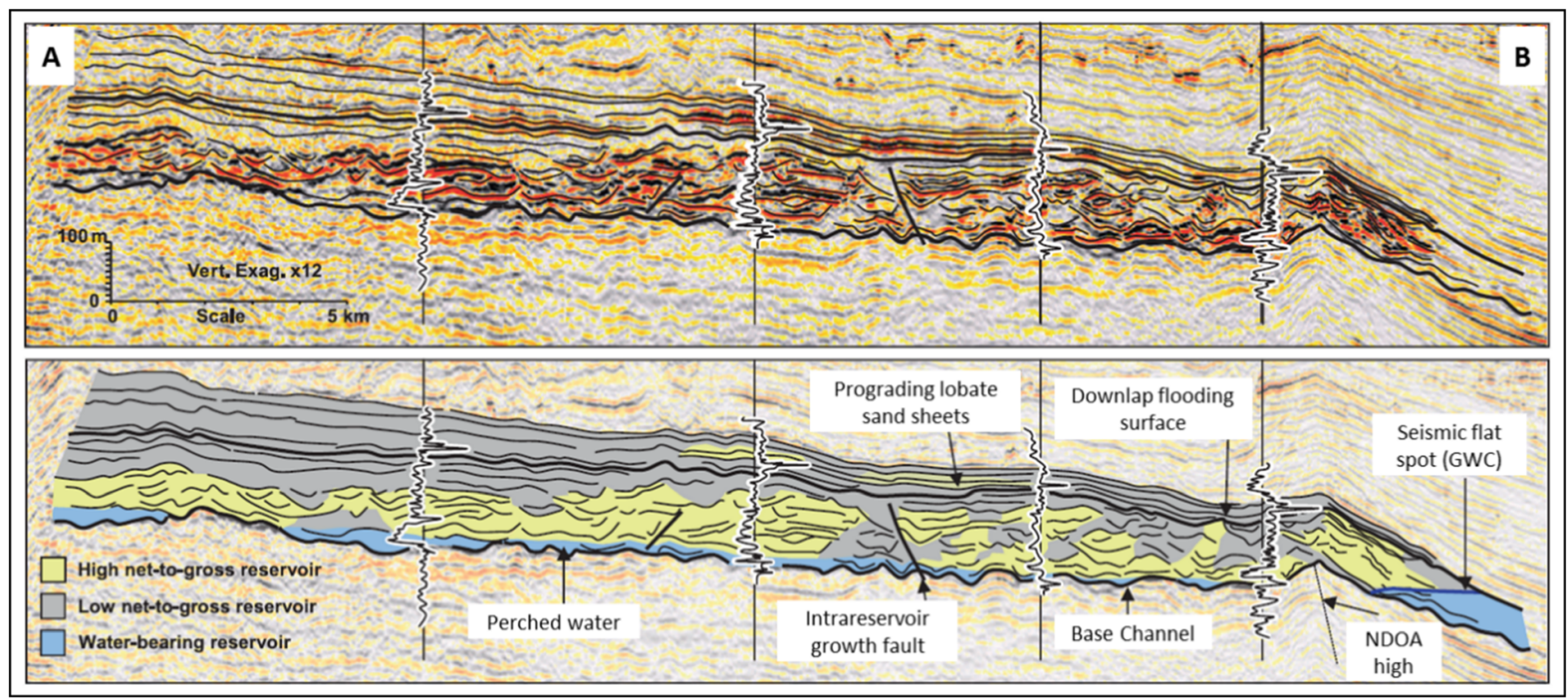

Fig. 4 An arbitrary seismic line (upper) and its interpretation (lower) through the Sequoia channel showing the reservoir facies. NDOA = Nile Delta offshore anticline. The location of this line can be seen in Fig. 2. Modified from Cross et al. (2009)

wells and six development wells. The exploration wells are: Sapphire-2 and Rosetta-10, and the development wells are: Sequoia-D1 to -D6. Sequoia-D5 well was not included in the study but used as a QC well. All wells have full suit of wireline $\operatorname{logs}$ include $S_{w}, \Phi$, and $V_{\text {sh }} \operatorname{logs}$.

Figure 5 shows the workflow steps. As a start, well $\operatorname{logs}$ QC and conditioning were applied to the input $\operatorname{logs}$ to make sure that the well logs are spike-free and con- sistent with the seismic data. After de-spiking the well $\operatorname{logs}$, all $\operatorname{logs}$ were resampled at $4 \mathrm{~ms}$ to match the seismic scale and smoothed. Then, the full-stack seismic volume was used as an engine to generate many internal attributes (i.e. amplitude-related attributes, frequencyrelated attributes, phase-related attributes ...etc.). The seismic-generated attributes (internal attributes) were used with the inverted volumes (external attributes). Using the stepwise-regression method, the best set of

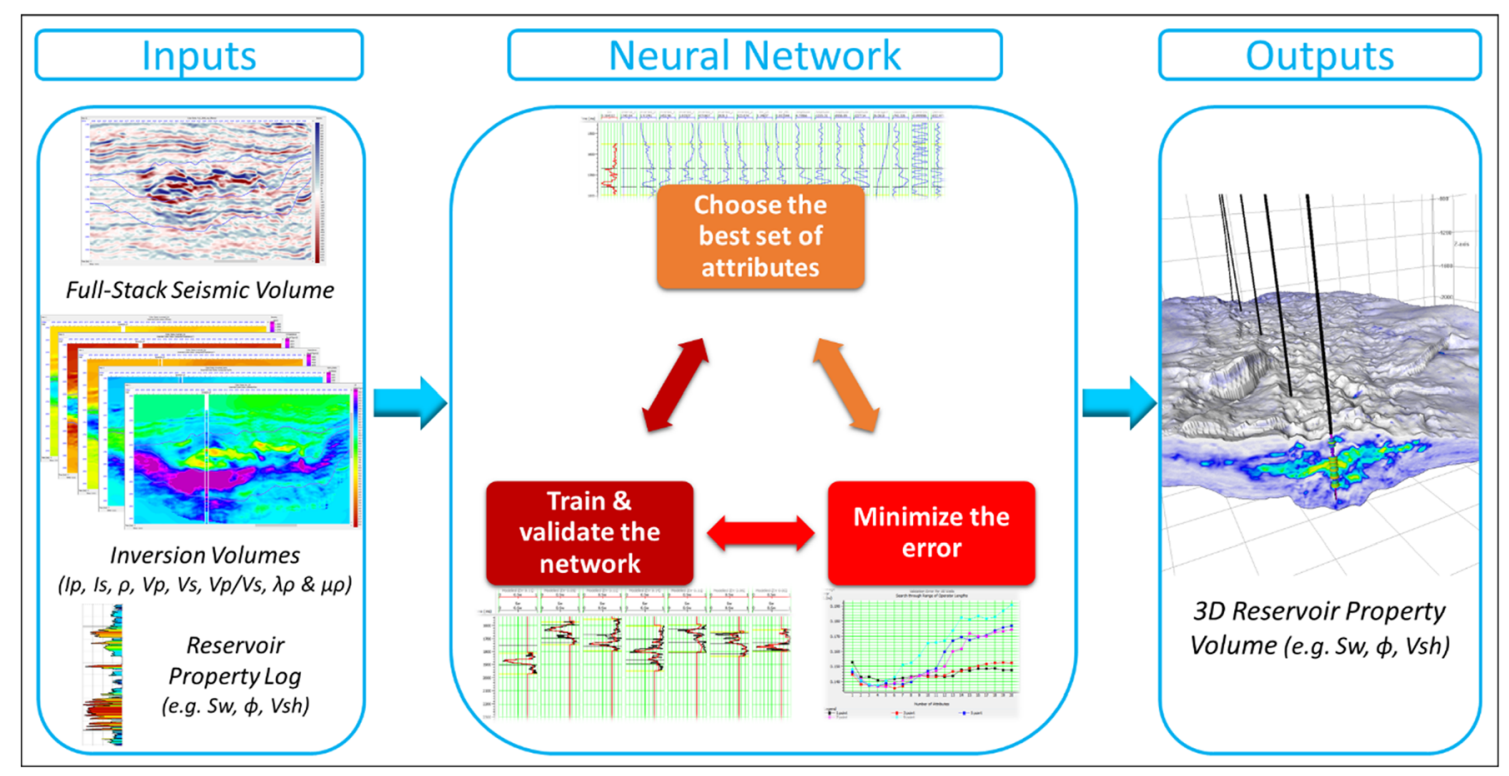

Fig. 5 The proposed workflow steps to predict the reservoir properties $\left(\mathrm{S}_{\mathrm{w}}, \Phi\right.$, and $\left.\mathrm{V}_{\mathrm{sh}}\right)$ via the $\mathrm{PNN}$ algorithm 
Table 1 The best set of attributes used to train the PNN for each property

\begin{tabular}{|c|c|c|c|}
\hline Reservoir's Property & Attribute order & Attribute Name & Attribute Type \\
\hline \multirow[t]{6}{*}{$S_{w}$} & 1 & $1 /\left(\mathrm{V}_{\mathrm{p}} \mathrm{V}_{\mathrm{s}}\right.$ ratio $)$ & External \\
\hline & 2 & $\mathrm{~V}_{\mathrm{s}}$ & External \\
\hline & 3 & $\operatorname{Sqrt}\left(V_{p}\right)$ & External \\
\hline & 4 & FrEq. filter $(5 / 10-15 / 20)$ & Internal \\
\hline & 5 & Amplitude-weighted phase & Internal \\
\hline & 6 & Cosine instant. phase & Internal \\
\hline \multirow[t]{5}{*}{$\Phi$} & 1 & $1 /\left(\mathrm{V}_{\mathrm{p}} \mathrm{V}_{\mathrm{s}}\right.$ ratio $)$ & External \\
\hline & 2 & $(\text { lambdaRho) })^{\wedge} 2$ & External \\
\hline & 3 & Log (MuRho) & External \\
\hline & 4 & TWT & Internal \\
\hline & 5 & FrEq. filter $(5 / 10-15 / 20)$ & Internal \\
\hline \multirow[t]{7}{*}{$V_{s h}$} & 1 & $1 /\left(\mathrm{V}_{\mathrm{p}} \mathrm{V}_{\mathrm{s}}\right.$ ratio $)$ & External \\
\hline & 2 & $(\text { lambdaRho })^{\wedge} 2$ & External \\
\hline & 3 & $\mathrm{~V}_{\mathrm{p}}$ & External \\
\hline & 4 & $\left(Z_{p}\right)^{\wedge} 2$ & External \\
\hline & 5 & FrEq. filter $(5 / 10-15 / 20)$ & Internal \\
\hline & 6 & Cosine instant. phase & Internal \\
\hline & 7 & TWT & Internal \\
\hline
\end{tabular}

seismic internal/external attributes were found. With these attributes, the prediction error is, statistically, the lowest. The best set of attributes for $S_{w}, \Phi$, and $V_{s h}$ prediction are listed in Table 1.

The conditioned well-log data and the best set of seismic (internal/external) attributes at well locations were fed to the PNN analysis for the training and validation of the networks. During the training step, the weights of the input attributes are modified to fit the target $\log$. At the same time, the networks are validated using the cross-validation technique, in which some wells were hidden, intentionally, and being predicted using the trained network. After minimizing the errors,

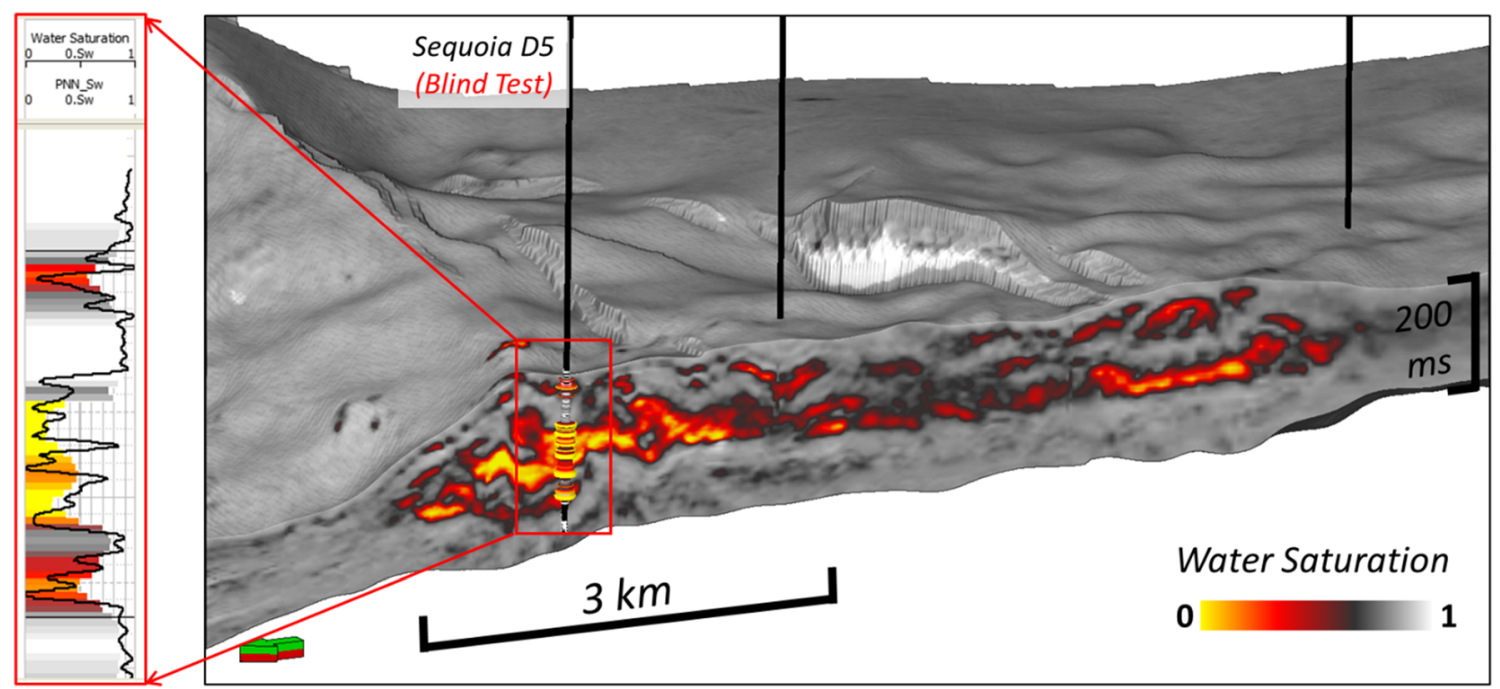

Fig. 6 A 3D view of the $S_{w}$ predicted volume through the blind well location. (Left) a comparison between the predictions (colored) and the actual well $\log$ (black curve) 


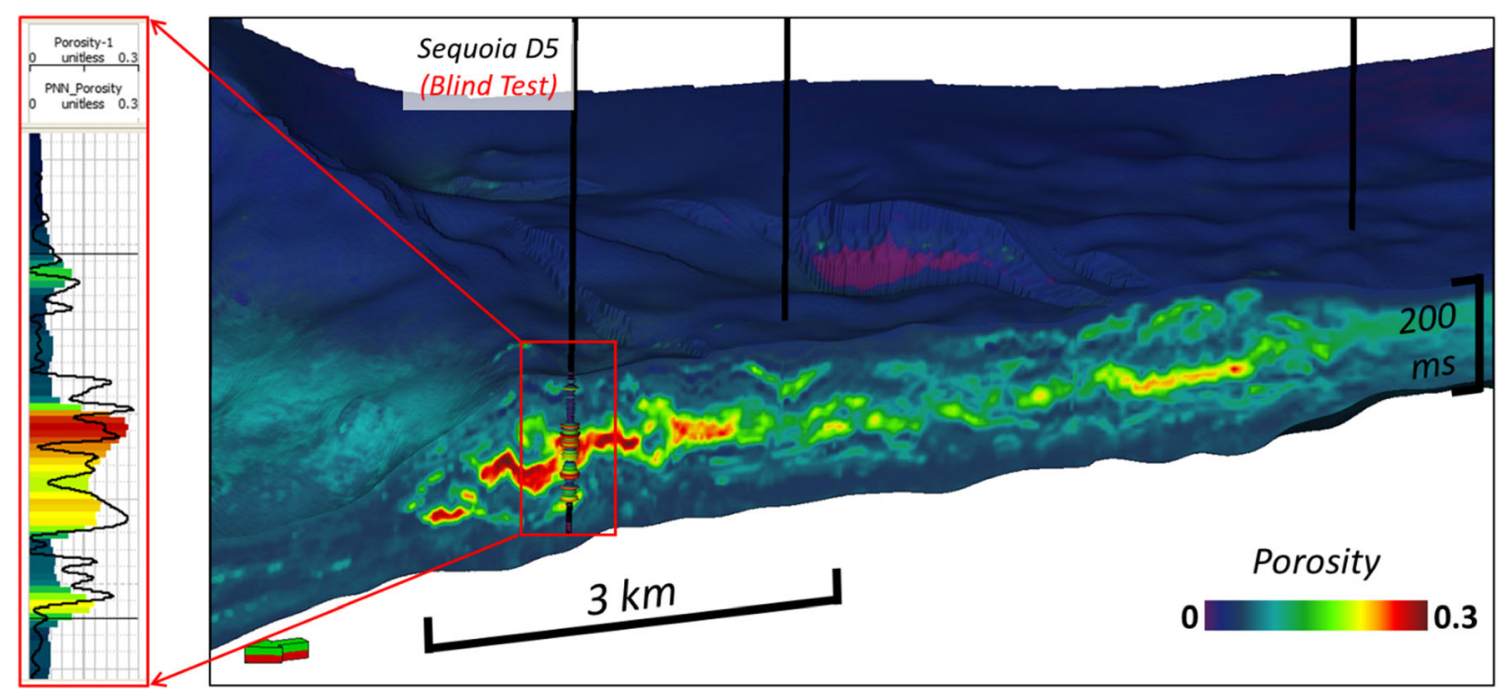

Fig. 7 A 3D view of the $\Phi$ predicted volume through the blind well location. (Left) a comparison between the predictions (colored) and the actual well $\log$ (black curve)

the trained networks are implemented to predict $S_{w}, \Phi$, and $V_{s h} 3 \mathrm{D}$ volumes through three separate runs.

\section{Results}

To measure the accuracy of the PNN results, two quantitative analyses method were applied. In the first analysis method, we check the similarity/correlation between the originally recorded logs and the modeled logs at well locations. The average normalized correlations for the $S_{w}, \Phi$, and $V_{s h}$ were $0.90,0.94$, and 0.94 , respectively. The second analysis method is the blind well test, in which Sequoia-D5 well was not included in the analysis for QC of estimation products.

The average correlations at the Sequoia-D5 well location for the $\mathrm{S}_{\mathrm{w}}, \Phi$, and $\mathrm{V}_{\mathrm{sh}}$ were $0.86,0.81$, and 0.82 , respectively. Figures 6, 7 and 8 show the results at the blind well location. The PNN resulting volumes $\left(S_{w}, \Phi\right.$, and $\left.V_{s h}\right)$ are aligned well with the originally recorded well logs. And apart from the well locations, these volumes are honoring the reservoir lateral

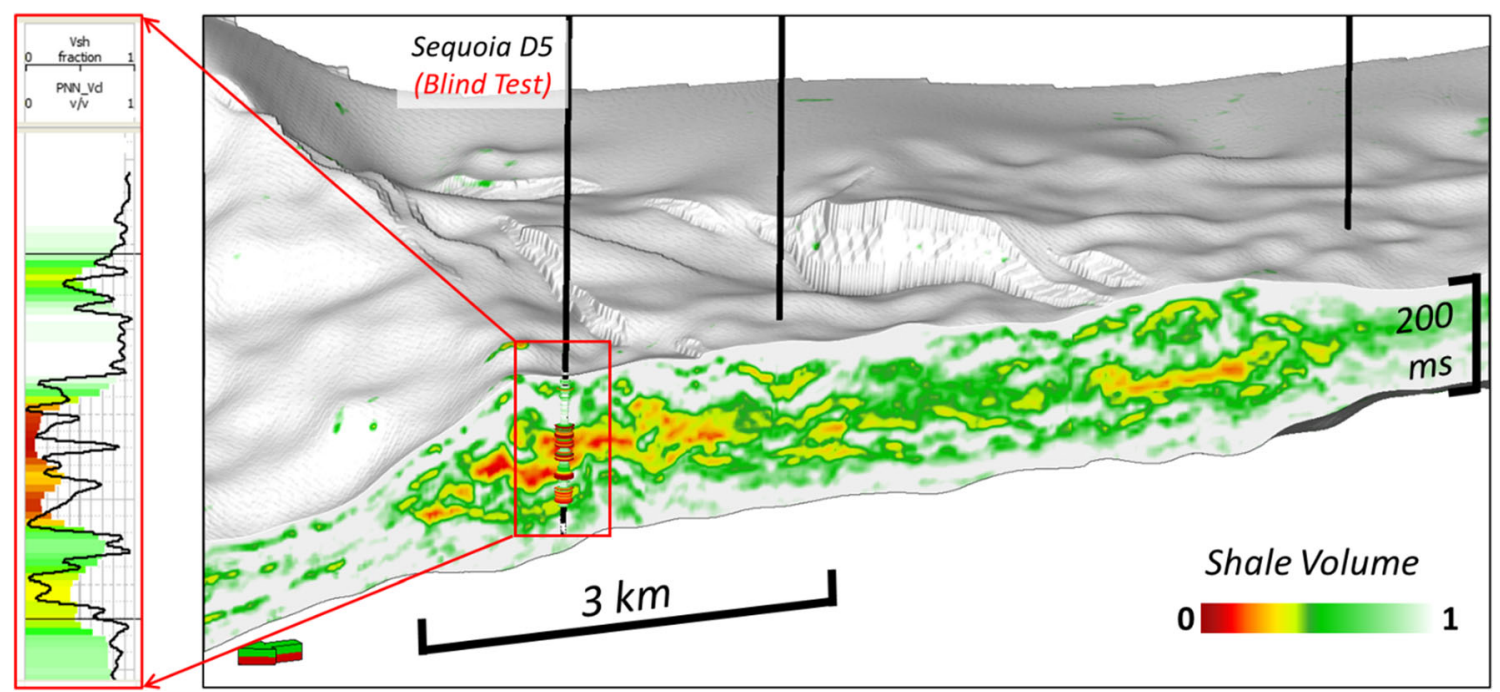

Fig. 8 A 3D view of the $\mathrm{V}_{\text {sh }}$ predicted volume through the blind well location. (Left) a comparison between the predictions (colored) and the actual well $\log$ (black curve) 
variability and show an interesting number of details. These details are very crucial for investigating reservoir compartmentalization and to reassess the remaining hydrocarbon reserves.

\section{Conclusions}

Considering the drawbacks of the conventional reservoir characterization methods, we used a PNN approach to shale-volume, effective porosity, and water saturation $3 \mathrm{D}$ volumes. Blind-well tests were performed to the resulted volumes. The predicted reservoir properties showed very good tie to the original logs, contain fine details, and honor reservoir heterogeneity between the wells. The resulted volumes can be used to refine the construction of a reservoir model and to reassess the remaining hydrocarbon reserves. The proposed approach provides a short and efficient approach to reservoir properties prediction.

Open Access This article is licensed under a Creative Commons Attribution 4.0 International License, which permits use, sharing, adaptation, distribution and reproduction in any medium or format, as long as you give appropriate credit to the original author(s) and the source, provide a link to the Creative Commons licence, and indicate if changes were made. The images or other third party material in this article are included in the article's Creative Commons licence, unless indicated otherwise in a credit line to the material. If material is not included in the article's Creative Commons licence and your intended use is not permitted by statutory regulation or exceeds the permitted use, you will need to obtain permission directly from the copyright holder. To view a copy of this licence, visit http://creativecommons.org/licenses/by/4.0/.

\section{References}

Adel AA, Othman TH, Abdelhafeez SE, Din M, Metwally, Ibrahim AM, El, Shafei (2017a) Petrophysical characteristics of the Messinian
Abu Madi and Qawasim formations in Abu Madi West development field,onshore Nile Delta, Egypt. al Azhar bulletin of science, vol 9th., conf., march 2017, p 137-158

Adel AA, Othman TH, Abdelhafeez SE, Din M, Metwally, Ibrahim AM, El, Shafei (2017b) Hydrocarbons implications in abu Madi West area offshore Central Nile Delta, Egypt. Al Azhar Bulletin of Science vol 9th., Conf., March 2017, p 273-289

Cozzi A, Cascone A, Bertelli L, Bertello F, Brandolese S, Minervini M, Ronchi P, Ruspi R, Harby H (2018) Zohr Giant Gas Discovery - A paradigm shift in Nile Delta and East Mediterranean Exploration: Discovery Thinking Forum AAPG/SEG International Conference and Exhibition, London, England

Cross NE, Cunningham A, Cook RJ, Taha A, Esmaiel E, El N Swidan (2009) Three-dimensional seismic geomorphology of a deep-water slope-channel system: The Sequoia field, offshore west Nile Delta, Egypt. AAPG Bull 93:1063-1086

Hampson DP, Schuelke J, Quirein J (2001) Use of multi-attribute transforms to predict log properties from seismic data. Geophysics 66: 220-236

Kirschbaum MA, Schenk C, Charpentier R, Klett T, Brownfield M, Pitman J, Cook T, Tennyson M (2010) Assessment of undiscovered oil and gas resources of the Nile Delta Basin Province, eastern Mediterranean: U. S. Geological Survey Fact Sheet, pp 2010-3027

Mohamed IA, El-Mowafy H, Kamel D, Heikal M (2014) Prestack seismic inversion versus neural-network analysis: A case study in the Scarab field offshore Nile Delta, Egypt. The Leading Edge, 33(5), 498-506. https://doi.org/10.1190/tle33050498.1

Mohamed IA, Shenkar O, Mahmoud H (2017) Understanding reservoir heterogeneity through water-saturation prediction via neural network - A case study from offshore Nile Delta. Lead Edge 36(4): 298-303

Rio D, Sprovieri R, Thunell R (1991) Pliocene-lower Pleistocene chronostratigraphy: A re-evaluation of Mediterranean type sections. GSA Bull 93:1049-1058

Russell BH (2014) Prestack seismic amplitude analysis: An integrated overview. Interpretation 2(2):SC19-SC36

Samuel A, Kneller B, Raslan S, Sharp A, Parsons C (2003) Prolific deepmarine slope channels of the Nile Delta, Egypt. AAPG Bull 87(4): $541-560$

Tharwat Abd El Hafeez., Hassan H El Kadi, El Geuoshi M (2014) Quantitative well-log analysis for evaluation instead of gas reservoirs at South Batra field, Nile Delta, Egypt. Austin J Earth Sci ((1) Id1005) 1(1):1-7

Publisher's note Springer Nature remains neutral with regard to jurisdictional claims in published maps and institutional affiliations. 